\title{
Caesarean delivery on maternal request: need to redefine in view of intrapartum cases
}

\author{
Kishore Bhanudasrao Atnurkar ${ }^{1 *}$, Arun Ramkrishnarao Mahale ${ }^{2}$
}

\author{
${ }^{1}$ Department of Obstetrics and Gynecology, Dass Clinic, Tilaknagar, Nanded, Maharashtra, India \\ ${ }^{2}$ Department of Obstetrics and Gynecology, Mahale Hospital, Borban, Vazirabad, Nanded, Maharashtra, India
}

Received: 09 December 2021

Accepted: 05 January 2022

\section{*Correspondence:}

Dr. Kishore Bhanudasrao Atnurkar,

E-mail: atnurkakishore@gmail.com

Copyright: () the author(s), publisher and licensee Medip Academy. This is an open-access article distributed under the terms of the Creative Commons Attribution Non-Commercial License, which permits unrestricted non-commercial use, distribution, and reproduction in any medium, provided the original work is properly cited.

\begin{abstract}
Background: The objective of the study was to analyse the data of caesarean section on maternal request (CDMR) both before labour and intrapartum, in low-income society from a town in India.

Methods: It was a retrospective observational study of 9331 caesarean section (CS) cases carried out in different small private maternity hospitals over a period of 20 years. We used the data for auditing the CS cases done on maternal request.

Results: Out of $9331 \mathrm{CS}$ cases documented, $216 \mathrm{CS}$ were done on maternal request. The incidence of CDMR was $2.31 \%$. About one third cases were intra-partum. The rising trend of CDMR was observed both before labour and intrapartum.

Conclusions: There was a need to redefine CDMR in the view of rise in the incidence of women requesting for CS not only before labour but during lab or also. CDMR is no more confined to highly educated, rich and women from urban area. Less educated, low income group women residing in rural area are also becoming aware that CS can be done on maternal request.
\end{abstract}

Keywords: Caesarean section, Caesarean section on demand, Caesarean section on request

\section{INTRODUCTION}

There is a global outcry on rising rate of caesarean section (CS). Indications for caesarean section are critically analysed to address this issue. One such area is CDMR (caesarean delivery on maternal request). It is justified on the grounds of mode of birth being the autonomy of the mother. The definition and factors leading to CDMR and measuring its prevalence are still hazy. Ethical, legal and related issues are not yet widely known. ${ }^{1}$ The debate over whether women should have the right to decide on their mode of birth is not a simple one. Although an increasing number of women seem to be requesting a CS, in some of those cases their decision was explicitly or implicitly supported by their obstetrician. ${ }^{2}$

Most of the literature is on CDMR before labour onset, as it is defined that way. Very few articles are on CDMR during labour. CS on maternal request is defined as a planned CS conducted on maternal request when there is no obstetric contraindication for vaginal delivery. ${ }^{3}$ The definition of CDMR includes the caesarean sections done on maternal request which are done before labour. The absolute proportion of CDMR varies between 0.2 and $42.0 \%$, with significant variations across studies and subgroups. ${ }^{4}$ We come across situations where some women either nulliparous or multiparous, (with or without previous CS) when hospitalized with labour pains, either immediately or after tolerating labour pains for few hours demand for cesarean section for some reason and cesarean section is done without any obstetric indication. The CS done in such situation needs to be included in the category of CDMR. We need to expand the present definition of CDMR as planned and intrapartum CS done on maternal request without obstetric and/or any medical reasons. We find very few studies in the literature related to intrapartum 
CDMR. The study published by Robin et al about 17 years back demonstrates that there is an important unrecognized discretionary grey zone in which physicians offer or women request caesarean delivery during labour. The study further emphasises the importance of defining the clinical entity of intrapartum elective caesarean delivery and the factors shaping it. Therefore it becomes necessary to explore when intrapartum elective caesarean delivery would be justified. ${ }^{5}$ In the efforts to explore, we need to find the answer to a question, 'How is women's demand for caesarean section measured?' According to a systematic literature review, measuring caesarean section demand is challenging because the factors leading to demand for caesarean section during childbirth while in the labour ward remains invisible. The magnitude of caesarean section on demand in low-income countries remains unclear due to the lack of studies conducted in these countries. ${ }^{6}$ The educational and economic status of the women has impact over the desire to have voluntary CS. There is evidence from National Family Health Survey 2015-16 (NFHS), regarding prevalence and determinants of voluntary caesarean deliveries and socioeconomic inequalities in India that older women, higher educated mothers, residing in urban areas and, belonging to high socio-economic status are the ones who opt for voluntary $\mathrm{C}$-section deliveries and seek private instructional delivery. ${ }^{7}$ In the efforts of reducing the incidence of CDMR, proper education of the patient and personal involvement of the treating obstetrician in counselling the patient and her supporters is essential. ${ }^{8}$

The purpose of the present study was to audit the data of CDMR cases to study the, profile of the women requesting for CS, carried out in single-handed-run small private hospitals. It is an endeavour to document and analyse CS demand both before labour and intrapartum, in lowincome country like India.

\section{METHODS}

The findings are based on the data of CS gathered over a period of 20 years. It was a retrospective observational study of 9331 caesarean section cases carried out in different small private maternity hospitals from 24 July 1999 to 23 July 2019 at a district place in western part of India. We used the data for auditing the CS cases done on maternal request. To understand the change over years and factors influencing CDMR the data was divided into four groups. Each group consists of number of CS done every five years. The author is a visiting obstetrician to many small maternity homes in the town. His participation in CS was either as a main surgeon or as an associate surgeon. He documented each case of CS, he participated. Author never got opportunity to counsel the women for deciding the mode of delivery. Moreover, he was called for CS after the decision of CS was made. He hardly noted any obstetrician with whom he worked, declining the proposal of CDMR.

Statistical analysis of the data was done by Epi Info 6 .
Ethical committee approval was not obtained as it was a retrospective observational study analysing the recorded data.

\section{RESULTS}

Out of $9331 \mathrm{CS}$ cases documented over a period of 20 years, $216 \mathrm{CS}$ were done on maternal request. The overall incidence of CDMR in our study was $2.31 \%$.

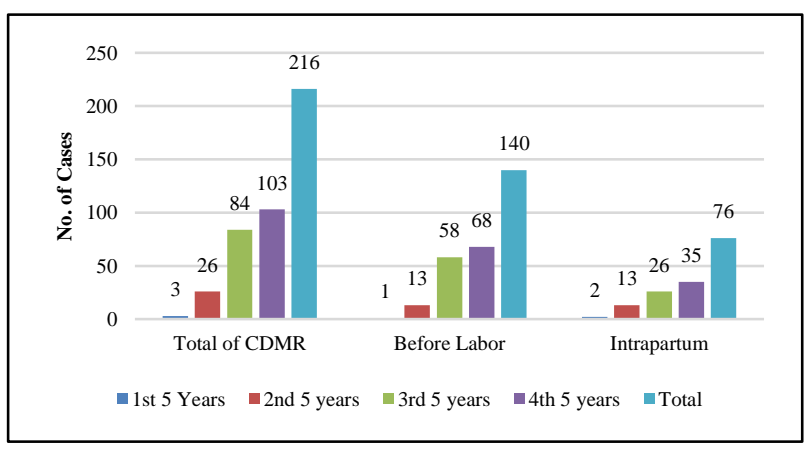

Figure 1: Distribution of CDMR cases done over a period of 20 years.

Table 1: Urban versus rural: year wise distribution.

\begin{tabular}{|llll|}
$\begin{array}{l}\text { Year wise } \\
\text { distribution }\end{array}$ & Urban $(\%)$ & Rural $(\%)$ & Total \\
\hline $\mathbf{1}^{\text {st }}$ five years & $01(33.33)$ & $02(66.66)$ & $03(1.38)$ \\
\hline $\mathbf{2}^{\text {nd }}$ five years & $20(76.92)$ & $06(23.07)$ & $26(12.03)$ \\
\hline $\mathbf{3}^{\text {rd }}$ five years & $69(82.14)$ & $15(17.85)$ & $84(38.88)$ \\
\hline $\mathbf{4}^{\text {th }}$ five years & $79(76.70)$ & $24(23.30)$ & $103(47.68)$ \\
\hline Total & $169(78.24)$ & $47(21.75)$ & 216 \\
\hline P value & p >0.05 insig. & \\
\hline & *Chi-sq test to compare two groups for significance, cal Chi- \\
sq=1.48 with Degrees of freedom (DF=2)
\end{tabular}

Both groups (urban and rural) do not differ significantly ( $p>0.05)$ from each other as regards their request for caesarean section on demand for non-medical reasons.

We documented CS done on maternal request both before labour and intraparum. Out of the 216 cases of CDMR, 140 cases $(64.81 \%)$ were done before labour and $76(35.18 \%)$ done intrapartum. The rising trend of CDMR cases was observed with each five year duration. The same pattern was seen in both the categories, before labour and intrapartum (Figure 1). Irrespective of whether CDMR was done before labour or intrapartum, majority of our patients $(78.24 \%)$ were from urban area. The rising trend of CDMR was also observed with each five years from both urban and rural area (Table 1). However, the percentage of intrapartum CDMR cases from both urban and rural area was almost same (Figure 2). It was found that majority of the CDMR patients belonged to higher educated group. Almost one fourth of the total CDMR cases were educated only up to $10^{\text {th }}$ standard. More percentage of educated patients demanded for CS before labour as compared to cases during labour. The percentage 
of less educated cases requesting for CS was $28.21 \%$ (Table 2). In our study, more percentage of cases belonged to low income group $(63.58 \%)$ as compared to high income group $(36.41 \%)$. Patients from low income group also requested for CS while in labour, the percentage of such cases was $36.90 \%$ (Table 3). CDMR was found more in nulliparous as compared to multiparous.

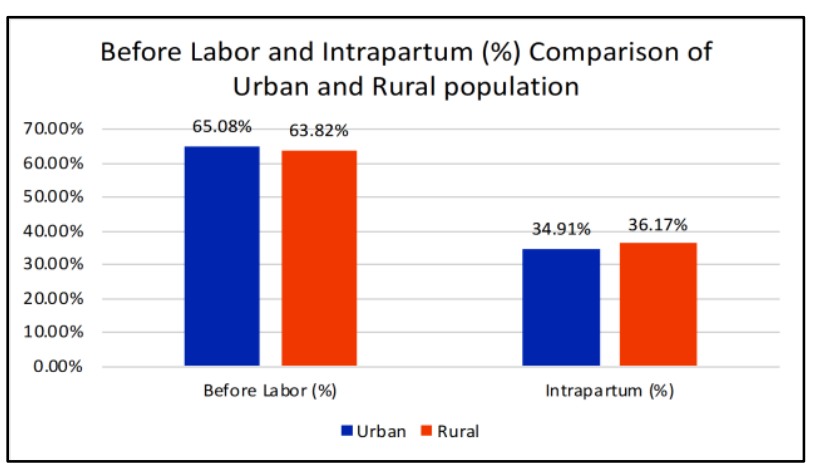

Figure 2: Before labour and intrapartum (\%) comparison of urban and rural.

Table 2: Educational Status.

\begin{tabular}{|c|c|c|c|}
\hline $\begin{array}{l}\text { Educational } \\
\text { status }\end{array}$ & $\begin{array}{l}\text { Before } \\
\text { labour } \\
(\%)\end{array}$ & $\begin{array}{l}\text { Intrapartum } \\
(\%)\end{array}$ & $\begin{array}{l}\text { Total }(\%) \\
(\mathrm{n}=216- \\
54=162)\end{array}$ \\
\hline Upto $10^{\text {th }}$ & $28(71.79)$ & $11(28.21)$ & $39(24.07)$ \\
\hline $\begin{array}{l}\text { Up to higher } \\
\text { secondary and } \\
\text { graduates }\end{array}$ & $39(63.93)$ & $22(36.07)$ & $61(37.65)$ \\
\hline $\begin{array}{l}\text { Higher } \\
\text { education }\end{array}$ & $42(67.74)$ & $20(32.26)$ & $62(38.27)$ \\
\hline \multicolumn{3}{|c|}{ Status not recorded } & 54 \\
\hline Total & 109 & 53 & 216 \\
\hline$P$ value & \multicolumn{3}{|c|}{$\mathrm{p}>0.05$ insig } \\
\hline
\end{tabular}

Requests from women those in labour and not in labour do not differ significantly $(\mathrm{p}>0.05)$ differ from each other as regards their request for caesarean section when considered by their educational status.

Table 3: Economic status of family.

\begin{tabular}{|c|c|c|c|}
\hline $\begin{array}{l}\text { Economic } \\
\text { status }\end{array}$ & $\begin{array}{l}\text { Before } \\
\text { labour } \\
(\mathrm{n}=216- \\
54=162)\end{array}$ & $\begin{array}{l}\text { Intrapartum } \\
(216-54=162)\end{array}$ & $\begin{array}{l}\text { Total } \\
(n=162)\end{array}$ \\
\hline $\begin{array}{l}\text { Low income } \\
\text { group }\end{array}$ & $65(63.10 \%)$ & $38(36.90 \%)$ & $\begin{array}{l}103 \\
(63.58 \%)\end{array}$ \\
\hline $\begin{array}{l}\text { High income } \\
\text { group }\end{array}$ & $44(74.57 \%)$ & $15(25.42 \%)$ & $\begin{array}{l}59 \\
(36.41 \%)\end{array}$ \\
\hline \multicolumn{3}{|c|}{ Status not recorded } & 54 \\
\hline Total & 109 & 53 & 216 \\
\hline
\end{tabular}

$*$ Chi-sq test to compare two groups for significance, cal Chi$\mathrm{sq}=2.24$ with Degrees of freedom $(\mathrm{DF}=1)$
Their economic status did not impact on their requests for caesarean section. Both groups are not significantly $(p>0.05)$ different from each other.

\section{DISCUSSION}

The incidence of CDMR varies between 0.2 and $42.0 \%$, with significant variations across studies and subgroups. ${ }^{4}$ In our series, we found the incidence to be $2.31 \%$. With each 5 years, the incidence is on rise in last 20 years. The present literature in its definition gives us understanding that CDMR is CS done before labour. Begum et al in their study mentioned lack of documentation of CDMR in the reasons for undertaking $\mathrm{CS}$, hence emphasized the importance of its documentation. ${ }^{4}$ In our study, we analysed our data of 20 years to know the contribution of CDMR both before labour and intrapartum, hence, our documentation and analysis is according to their suggestion. Our literature review defines CDMR as CS done on request before the onset of labour for nonmedical reasons except one study by Robin et al about 17 years back which mentions the need to include intrapartum request in the definition of CDMR. ${ }^{5}$ In our study, about one third of the cases of CDMR were done intrapartum,

Our results indicate that women from rural area also becoming aware that CS can be requested or demanded (Table 1). Same is true with the factors like educational and economic status of the women (Table 2, Table 3). It shows that CDMR is no more confined to a peculiar group of rich, highly educated, urban women as mentioned in NFHS 2015-16. ${ }^{7}$ Our observations indicate that about one third $(35.18 \%)$ of the total CDMR cases studied belong to intrapartum group. Rural, less educated, low income group also contribute to CDMR.

We need to address the situation in which the decision of CS on maternal request is taken intrapartum. These are some of the patients who contribute to CDMR, therefore, must be considered in the calculation of CDMR figures. Such cases will go unnoticed if not documented.

The whole discussion can be summarized with the conclusive remarks of the study of CDMR undertaken by Narayanaswamy et al, in a rural medical college that proper education of the patient and personal involvement of the treating obstetrician in counselling the patient and her supporters can reduce caesarean delivery for maternal request. $^{8}$

Our study does not address the factors favouring the decision of CDMR but previous unpleasant experience of vaginal birth, cost affordability, cost coverage by some agency, inadequate labour analgesia may be the reasons.

\section{CONCLUSION}

As against most of the studies in the literature, one third of requests for $\mathrm{CS}$ were during labour. The results of the present study bring forward few important issues related to 
CDMR. There is need to redefine CDMR in the view of rise in the incidence of women requesting for CS not only before labour but during labour also. This group is silently gathering its place in the list of nonmedical indications of CS. Secondly, CDMR is no more confined to a group of women who are highly educated, belong to high income group and reside in urban area. Less educated, low income group women residing in rural area are also becoming aware that CS can be done on maternal request. Ignoring intrapartum CDMR would give a considerable setback to the worldwide efforts of reducing the incidence of CS. It's a word of caution to the whole world of caesarean section that CDMRs both before and intrapartum are showing an increasing trend which is likely to change the entire perception of child birth process. Indeed, CS is not only becoming doctor friendly procedure for obstetricians but for the people in the society as well.

\section{ACKNOWLEDGMENTS}

We thank all the owner obstetricians of small private maternity hospitals for permitting us to use the caesarean section data for this study. We also thank Mr. Malhar Lathkar, Mrs Anshul VA, Santosh Bakshi and Mr. Kadam from Solapur for helping us in statistical analysis of the collected data.

Funding: No funding sources Conflict of interest: None declared

Ethical approval: Not required as it is a retrospective data analysis

\section{REFERENCES}

1. Chervenak F, McCullough L. Responding professionally to requests for cesarean delivery. Georgian Med News. 2017;(268-269):7-11.
2. Loke AY, Davies L, Mak YW. Is it the decision of women to choose a cesarean section as the mode of birth? A review of literature on the views of stakeholders. BMC Pregnancy Childbirth. 2019;19:286.

3. Eide KT, Morken NH, Bærøe K. Maternal reasons for requesting planned cesarean section in Norway: a qualitative study. BMC Pregnancy Childbirth. 2019;19:102.

4. Begum T, Saif-Ur-Rahman KM, Yaqoot F, Stekelenburg J, Anuradha S, Biswas T, et al. Global incidence of caesarean deliveries on maternal request: a systematic review and meta-regression. BJOG. 2021;128(5):798-806.

5. Kalish RB, McCullough L, Gupta M, Thaler HT, Chervenak FA. Intrapartum elective cesarean delivery: a previously unrecognized clinical entity. Obstet Gynecol. 2004;103(6):1137-41.

6. Schantz C, de Loenzien M, Goyet S, Ravit M, Dancoisne A, Dumont A. How is women's demand for caesarean section measured? A systematic literature review. PLoS One. 2019;14(3):e0213352.

7. Singh SK, Vishwakarma D, Sharma SK. Prevalence and determinants of voluntary caesarean deliveries and socioeconomic inequalities in India: Evidence from National Family Health Survey (2015-16). Clin Epidemiol Glob Health. 2020;8(2):335-42.

8. Narayanaswamy M, Ambika B, Sruthi T. Cesarean delivery at maternal request in a rural medical college hospital. J Clin Gynecol Obstet. 2016;5(2):64-7.

Cite this article as: Atnurkar KB, Mahale AR. Caesarean delivery on maternal request: need to redefine in view of intrapartum cases. Int J Reprod Contracept Obstet Gynecol 2022;11:501-4. 